\title{
Are Mentalizing Abilities and Insight Related to the Severity of Obsessive-Compulsive Disorder
}

\author{
Leman İnanç ${ }^{1}{ }^{\circledR}$, and Merih Altıntaş ${ }^{2}$ \\ ${ }^{1}$ Department of Psychiatry, Faculty of Medicine, Muğla Sıtkı Koçman University, Muğla, Turkey \\ ${ }^{2}$ Erenköy Mental Health and Research Hospital, İstanbul, Turkey
}

Objective The aim of this study is to investigate whether insight and mentalizing abilities are related to the severity of Obsessive Compulsive Disorder (OCD) in treatment resistant OCD. We look at the association between treatment resistance, insight, and mentalizing ability.

Methods The study was conducted with 71 OCD patients; 30 of them met the criteria for treatment resistant OCD, whereas the other 41 (57.7\%) were labeled as responder group. All patients were assessed with the Yale-Brown Obsessive-Compulsive Scale (Y-BOCS), Reading the Mind in the Eyes Test (RMET), Brown Assessment of Beliefs Scale (BABS), Mini International Neuropsychiatric Interview, Beck Depression Inventory, and Beck Anxiety Inventory.

Results The resistant group received higher depression and anxiety mean scores and had significantly longer illness duration. The RMET score was significantly higher for responders. The Y-BOCS insight score and the BABS score were significantly higher for the resistant group. BABS scores were negatively correlated with RMET total scores. RMET scores were found to be significant predictor of insight even when other potential factors were controlled for.

Conclusion Results suggest that better mentalizing abilities may be a predictor of better treatment outcome in patients with OCD.

Psychiatry Investig 2018;15(9):843-851

Key Words Obsessive compulsive disorder, Mentalizing, Insight.

\section{INTRODUCTION}

Obsessive-compulsive disorder (OCD) is characterized by intrusive thoughts, images, and ritualistic behaviors. It is a frequent, debilitating neuropsychiatric disorder affecting approximately $1-3 \%$ of the general population. OCD has long courses, high tendency to relapse, and adverse impacts on multiple dimensions of social functioning. ${ }^{1-4}$

First-line treatments for OCD include nearly all selective serotonin reuptake inhibitors (SSRIs), clomipramine, and cognitive-behavior therapy (CBT). ${ }^{5}$ Approximately 40 to $60 \%$ of OCD patients are resistant to standard therapeutic strategies. The term "resistant" indicates the failure of at least two adequate therapeutic trials of serotonin reuptake inhibi-

Received: February 22, 2018 Revised: April 16, 2018

Accepted: May 2, 2018

$\triangle$ Correspondence: Leman İnanç, MD

Department of Psychiatry, Faculty of Medicine, Muğla Sıtkı Koçman University, 48000 Kötekli Muğla, Turkey

Tel: +90 252214 13 26, Fax: +90 25221235 99, E-mail: leman.inanc@gmail.com (c) This is an Open Access article distributed under the terms of the Creative Commons Attribution Non-Commercial License (https://creativecommons.org/licenses/by$\mathrm{nc} / 4.0$ ) which permits unrestricted non-commercial use, distribution, and reproduction in any medium, provided the original work is properly cited. tors (SRIs). ${ }^{6-8}$

Research about clinical predictors of resistance has been conducted to estimate the prognoses and compose guidelines for treatment of OCD. Several studies have reported that gender, ${ }^{9}$ age of onset, ${ }^{9,10}$ family history of $\mathrm{OCD},{ }^{11}$ sexual and religious obsessions and/or compulsions, ${ }^{9}$ duration of illness, ${ }^{12,13}$ especially bipolar and attention deficit and hyperactivity disorder comorbidity, ${ }^{3}$ and the absence of insight. ${ }^{13-15}$

The degree of insight is based on individuals ability to recognize the irrationality of OCD symptoms. ${ }^{15}$ Numerous studies indicate the role of insight in the treatment resistance in OCD. ${ }^{7,15-21}$ Insight is regarded as a multidimensional concept, comprising awareness of symptoms of illness, and awareness of need for treatment, or the psychosocial consequences of the illness. ${ }^{22}$ Investigating which factors are specifically related to poor insight is of crucial importance for understanding treatment resistant OCD and for further development of treatment strategies.

There is an increasing interest in the possible association between the insight and the social cognition. Studies of social cognition commonly focus on theory of mind (ToM) or men- 
talizing skills. ToM is often taken as synonymous with mentalizing ability. ${ }^{23,24}$ Mentalizing ability is the ability to understand mental states and emotions of oneself and others. ${ }^{25,26}$ This is the process where we see ourselves from the others point of view. Mentalizing and insight are overlapping concepts to a certain degree. The lack of insight is stated as a difficulty of making sense of ourselves or disturbance of the "selfmonitoring capacity". ${ }^{27}$ Awareness of illness needs a third person's view of self, evaluating oneself relative to others; that is the mentalizing ability itself. ${ }^{12}$ Insight helps a patient to imagine what others think about their illness, their life, their symptoms and it provides a window to others' views of their symptoms. ${ }^{28}$ Fonagy reveals that understanding mental illness and its treatment requires mentalizing ability. ${ }^{29,30}$

Insight and mentalizing deficits in patients with OCD have been studied separately in previous research. Clinical studies have reported that emotional awareness and perception deficits are more prevalent among patients with OCD compared to normal subjects. ${ }^{26} \mathrm{OCD}$ patients demonstrated poorer performance on mentalizing tasks than healthy controls. ${ }^{31}$ Several studies show that OCD patients have difficulties in emotional perception and empathy. ${ }^{32,33}$ Kang et al. ${ }^{32}$ emphasized that emotional awareness deficit could be in a crucial importance of maintenance of obsessive-compulsive symptoms.

Several studies found evidence of specific strong correlation between insight and mentalizing. ${ }^{28,34-36}$ Bora et al..$^{35}$ suggested that mentalizing abilities were very important for the awareness of illness and that these two concepts were very similar. It would be valuable if the relationship could be identified between treatment resistance, insight and mentalizing in patients with OCD. Despite the clinical significance of this relationship, no study to date has reported this association and its impact on treatment response in OCD. The aim of the present study is to investigate whether insight and mentalizing ability are related to severity of OCD. We hypothesize that there is a negative correlation between the mentalizing ability and the severity of the OCD symptoms. We also intend to examine the association between insight and mentalizing ability with the hypothesis that impaired mentalizing predicts poor insight in patients with OCD. Additionally, we want to investigate the extent to which this association reflects a direct connection, or if such connection is mediated by other factors.

\section{METHODS}

The sample consisted of 71 consecutive admissions to the adult in- and outpatient clinics at a psychiatric research and education hospital. Participants were patients aged 18 years or over, with a primary diagnosis of $\mathrm{OCD}$, as determined by the Structured Clinical Interview for DSM-IV (SCID-I). Exclusion criteria included active schizophrenia or psychosis, acute suicidality, substance abuse, organic brain disorder, severe mental retardation that does not permit an evaluation to characterize OCD, or OCD symptoms that occur exclusively in the context of depression. Fifty eight (42.3\%) of these participants were labeled as "treatment resistant OCD" (resistant group) due to failure of at least two medication trials or one adequate treatment trial like psychodynamic therapy or $\mathrm{CBT}^{6-8}$ Subjects were considered treatment responsive OCD patients (responder group) if, after treatment with any conventional therapy, they presented at least a $35 \%$ decrease in the initial Y-BOCS score and had maintained improvement for at least 12 months. We did not preselect for treatment-resistant participants; these were the individuals who sought treatment and thus represented a naturalistic sample. The study was approved with number 10, on 02 February 2013, by the Local Ethical Committee. After complete description of the study to the participants, written informed consent was obtained.

\section{Measurements}

\section{Demographic characteristics}

Structured questions were used to determine socio-demographic characteristics.

\section{DSM-IV diagnosis}

To establish OCD diagnosis, relevant section of the Structured Clinical Interview for DSM-IV Axis I Disorders (SCID-I) was used for all patients. ${ }^{37}$

\section{OCD severity}

Yale-Brown Obsessive-Compulsive Symptoms Scale (YBOCS) is a 10 item clinician-rated test used to assess severity of obsessive compulsive symptoms in OCD patients. ${ }^{38}$ Each item is rated by clinician on a Likert-type scale $(0-4)$. Total possible score ranges from 0 to 40 . Specific symptoms were assessed using the Y-BOCS Symptom Checklist (Y-BOCS-SC). To determine the insight degree of patients we also rated item 11. The reliability and validity of Turkish version of the scale showed suitable psychometric properties and performance. ${ }^{39}$

\section{Depression}

Severity of the cognitive, affective and somatic symptoms of depression was evaluated using the Turkish version of the Beck Depression Inventory (BDI). ${ }^{40}$ The BDI is a 21 -item self-report inventory, which has been shown to be a reliable and valid measure of depression severity in both clinical and non-clinical populations. ${ }^{41}$ The patients have to choose one 
of the four statements in accordance with their feelings during the past week. Total scores vary between 0 and 63 .

\section{Anxiety}

The Beck Anxiety Inventory (BAI $)^{42}$ is a 21 -item self-report measure, used to assess the severity of anxiety symptoms. The patients are asked to rate to which extent they have been bothered by certain anxiety symptoms during the last week, on a 4-point Likert-type scale ranging from 0 (not at all) to 3 (severely, I could barely stand it). The total score ranges from 0 to 63 . The reliability and validity of the Turkish version BAI have been demonstrated. ${ }^{43}$

\section{Mentalizing ability}

Reading the Mind in the Eyes Test (RMET) is an inventory designed to measure adults' advanced mentalizing ability. Participants are shown a series of 32 photographs of the eyeregion of the face of different people. The original task comprises 36 pictures. ${ }^{44}$ Patients should choose the option that the best describes mental state in the picture. Photographs are all black and white and include male and female eyes in an equal number. The test provides a global score of the number of correctly identified mental states. Maximum score is 32 and the minimum is zero. This task also includes a glossary of all the mental state terms used, which participants could apply before or during the task. The reliability and validity of the Turkish version have been demonstrated. ${ }^{45}$

\section{Insight}

The Brown Assessment of Beliefs Scale (BABS) is a sevenitem clinician-rated scale that measures insight/delusionality. ${ }^{46}$ Items one to six are rated from 0 to 4 , the maximum score being 24 , with higher scores indicating poorer insight.
Ratings represent an average score for the past week. This scale is suitable for use in a broad range of psychiatric disorders The reliability and validity of the Turkish version have been demonstrated. ${ }^{47}$

\section{Data analyses}

Clinical data were expressed as percentages or mean values \pm standard deviation. Comparisons of demographic and clinical data were made with two-tailed unpaired t-tests for continuous variables and chi-square analysis for nominal data. Pearson's correlations were performed to determine the relationships between clinical variables. To assess the contribution of each of the selected explanatory variables to insight status, logistic regression analysis was used. Statistical significance was set at 0.05 . The data analyses were computed using SPSS, version 16.0 (SPSS Inc., Chicago, IL, USA).

\section{RESULTS}

The sample consisted of 71 subjects (20 males, 51 females) fulfilling diagnostic criteria for OCD by the DSM IV, with a mean $( \pm S D)$ age of $32.58 \pm 9.40$ years and an age range of 18 to 58 years. Thirty $(42.3 \%)$ of these patients met the criteria for treatment-resistant OCD (resistant group) whereas the others $41(57.7 \%)$ were labeled as responder group. General demographic and clinical data of the patients with OCD are shown in Table 1. Responder and resistant groups were similar in terms of age, gender and education. As indicated in Table 1, patients from the resistant group had significantly longer duration of the illness than the responders.

The severity of obsessive compulsive symptoms was significantly higher for treatment-resistant patients (Table 1).

Resistant group also received significantly higher mean

Table 1. Comparison of demographic and clinical variables between respondent and resistant OCD groups

\begin{tabular}{|c|c|c|c|c|}
\hline Clinical characteristics & Resistant group $(\mathrm{N}=30)$ & Responder group $(\mathrm{N}=41)$ & Analysis $\left(\mathrm{t}\right.$ or $\left.\chi^{2}\right)$ & $\mathrm{p}$ value \\
\hline Age (years) & $32.83 \pm 9.02$ & $32.39 \pm 9.77$ & 0.195 & 0.846 \\
\hline Gender (female) & $22(73.3 \%)$ & $29(70.7 \%)$ & 0.058 & 0.810 \\
\hline Education (years) & $9.93 \pm 5.74$ & $11.68 \pm 4.89$ & 1.385 & 0.171 \\
\hline Duration of illness (years) & $10.83 \pm 8.47$ & $7.02 \pm 7.00$ & 2.071 & $0.042^{*}$ \\
\hline Y-BOCS obsessions & $18.27 \pm 1.76$ & $10.68 \pm 3.10$ & 12.034 & $0.000^{*}$ \\
\hline Y-BOCS compulsions & $17.97 \pm 2.88$ & $10.02 \pm 3.70$ & 9.782 & $0.000^{*}$ \\
\hline Y-BOCS insight & $2.77 \pm 1.01$ & $0.83 \pm 0.74$ & 9.364 & $0.000^{*}$ \\
\hline Beck Depression Inventory & $26.83 \pm 13.25$ & $17.90 \pm 12.23$ & 2.933 & $0.005^{*}$ \\
\hline Beck Anxiety Inventory & $26.43 \pm 13.40$ & $18.83 \pm 14.21$ & 2.281 & $0.026^{*}$ \\
\hline RMET & $17.67 \pm 5.25$ & $21.56 \pm 4.48$ & 3.363 & $0.001^{*}$ \\
\hline BABS & $21.97 \pm 5.89$ & $13.59 \pm 5.49$ & 6.163 & $0.000^{*}$ \\
\hline
\end{tabular}

*values are significant. Y-BOCS: Yale-Brown Obsessive-Compulsive Symptoms Scale, RMET: Reading the Mind in the Eyes Test, BABS: Brown Assessment of Beliefs Scale 
scores of depression and anxiety than responders (Table 1).

RMET scores were significantly lower for the resistant group than for the responder group (Table 1).

A comparison of the content of obsessive compulsive symptoms is presented in Table 2 . We found a statistically significant difference between the two groups for religious $(\mathrm{p}=0.043)$ and somatic content $(\mathrm{p}=0.023)$ of obsessions, and compulsions of ordering/arranging $(\mathrm{p}=0.015)$ which were more frequently in the resistant group.

Pearson correlation analyses indicated that Y-BOCS total scores as well as obsessions, compulsions, and insight subscale scores were significantly correlated with BABS. BABS total score is correlated with RMET score. RMET scores were also correlated with Y-BOCS total scores as well as obsessions, compulsions, and insight subscale scores. Results obtained from Pearson correlation analyses are presented in Table 3.

To explore which clinical variables lead to a greater risk for poor insight in both resistant and responder OCD patients, logistic regression equation was estimated (Table 4). Dependent variable was insight (i.e. poor insight vs. good insight), while independent variables involved treatment-resistance, duration of illness, severity of obsessive and compulsive symptoms, degree of anxiety (BAI) and depression (BDI), and mentalizing (RMET) scores. The results of this logistic regression analysis indicated that mentalizing (RMET) scores were significant $(\mathrm{df}=1, \mathrm{p}=0.012)$ predictor of the insight (94.4\% correct) even when other potential factors were controlled for.

\section{DISCUSSION}

The present study examined the association between mentalizing, insight and treatment resistance in patients with OCD. To our knowledge, this is the first study assessed this relationship in OCD. Majority of previous research have investigated the association between mentalizing and insight in patients with a psychotic disorders. ${ }^{35,48,49}$ As expected, the findings of the current study provide an evidence for a significant relationship between treatment outcome, insight, and mentalizing in a clinical OCD sample.

Table 2. Obsessive compulsive symptom dimensions according to the yale-brown obsessive compulsive scale

\begin{tabular}{|c|c|c|c|c|}
\hline Y-BOCS symptom dimensions & $\begin{array}{c}\text { Resistant group }(\mathrm{N}=30) \\
\mathrm{N}(\%)\end{array}$ & $\begin{array}{c}\text { Responder group }(\mathrm{N}=41) \\
\mathrm{N}(\%)\end{array}$ & Analysis $\left(\chi^{2}\right)$ & $\mathrm{p}$ value \\
\hline \multicolumn{5}{|l|}{ Y-BOCS obsessions of } \\
\hline Aggression & $22(73.3)$ & $25(61.0)$ & 1.182 & 0.277 \\
\hline Contamination & $27(90.0)$ & $30(73.2)$ & 3.099 & 0.078 \\
\hline Sexual content & $11(36.7)$ & $9(22.0)$ & 1.854 & 0.173 \\
\hline Hoarding/saving & $7(23.3)$ & $9(22.0)$ & 0.019 & 0.890 \\
\hline Religiosity & $19(63.3)$ & $16(39.0)$ & 4.096 & $0.043^{*}$ \\
\hline Symmetry or exactness & $15(50.0)$ & $13(31.7)$ & 2.427 & 0.119 \\
\hline Somatic content & $16(53.3)$ & $11(26.8)$ & 5.164 & $0.023^{*}$ \\
\hline Other contents & $27(90.0)$ & $33(80.5)$ & 1.197 & 0.274 \\
\hline \multicolumn{5}{|l|}{ Y-BOCS compulsions of } \\
\hline Cleaning/washing & $24(80.0)$ & $25(61.0)$ & 2.932 & 0.087 \\
\hline Repeating/checking & $20(66.7)$ & $25(61.0)$ & 0.242 & 0.623 \\
\hline Counting & $13(43.3)$ & $14(34.1)$ & 0.620 & 0.431 \\
\hline Ordering arranging & $14(46.7)$ & $8(19.5)$ & 5.973 & $0.015^{*}$ \\
\hline Hoarding/collecting & $6(20.0)$ & $6(14.6)$ & 0.355 & 0.551 \\
\hline Other contents & $24(80.0)$ & $23(56.1)$ & 4.423 & $0.035^{*}$ \\
\hline
\end{tabular}

*values are significant. Y-BOCS: Yale-Brown Obsessive-Compulsive Symptoms Scale

Table 3. Correlations between clinical measurements and symptom dimensions of OCD in the whole sample

\begin{tabular}{lccccc}
\hline \multicolumn{1}{c}{ Clinical measurements } & Y-BOCS total & Y-BOCS obsessions & Y-BOCS compulsions & Y-BOCS insight & RMET \\
\hline BABS & $0.725^{*}$ & $0.729^{*}$ & $0.691^{*}$ & $0.840^{*}$ & $-0.681^{*}$ \\
RMET & $-0.480^{*}$ & $-0.468^{*}$ & $-0.470^{*}$ & $-0.692^{*}$ & \\
\hline
\end{tabular}

*correlation is significant at the 0.01 level. Y-BOCS: Yale-Brown Obsessive-Compulsive Symptoms Scale, RMET: Reading the Mind in the Eyes Test, BABS: Brown Assessment of Beliefs Scale 
Table 4. Logistic regression predicting insight in patients with OCD

\begin{tabular}{|c|c|c|c|c|c|c|}
\hline Variables & $\mathrm{B}^{*}$ & $\mathrm{SE}^{\dagger}$ & Wald $^{\ddagger}$ & $\mathrm{df}$ & $\mathrm{p}^{\S}$ & $\operatorname{Exp}(B)^{\|}$ \\
\hline Group (resistant/responder) & 1.735 & 2.900 & 0.358 & 1 & 0.550 & 5.666 \\
\hline Duration of illness (years) & 0.140 & 0.101 & 1.933 & 1 & 0.164 & 1.150 \\
\hline Y-BOCS obsessions & 0.550 & 0.463 & 1.412 & 1 & 0.235 & 1.733 \\
\hline Y-BOCS compulsions & 0.413 & 0.336 & 1.511 & 1 & 0.219 & 1.511 \\
\hline Beck anxiety inventory & -0.008 & 0.067 & 0.015 & 1 & 0.901 & 0.992 \\
\hline Beck fepression inventory & 0.019 & 0.066 & 0.085 & 1 & 0.771 & 1.019 \\
\hline RMET & -0.487 & 0.193 & 6.380 & 1 & $0.012^{\pi}$ & 0.615 \\
\hline
\end{tabular}

*these are the values for the logistic regression equation for predicting the dependent variable from the independent variable, ${ }^{\text {these }}$ are the standard errors associated with the coefficients, ${ }^{\ddagger}$ wald test is used in testing the null hypothesis that the coefficient is zero, \$this is the 2-tailed p-value associated with the Wald test. It is used as a measure of statistical significance of the coefficient, "these are the odds ratios for the predictors, Tvalues are significant. Y-BOCS: Yale-Brown Obsessive-Compulsive Symptoms Scale, RMET: Reading the Mind in the Eyes Test

Assessed by the means of the BABS and Y-BOCS, insight was significantly associated with OCD severity in our study. Pearson correlation analyses indicated that Y-BOCS total scores as well as obsessions, compulsions, and insight subscale scores were significantly correlated with BABS total scores. Current severity of obsessive compulsive symptoms was significantly higher for treatment-resistant patients.

Several studies have shown that patients with poor insight are less responsive to standard pharmacotherapeutic treatments ${ }^{17,19,50}$ and to behavioral therapy ${ }^{51,52}$ However, there is conflicting data on this point in the literature as some other studies did not find significant correlation between OCD insight, severity ${ }^{53}$ and treatment response..$^{54}$ Eisen et al..$^{53}$ suggested that similar levels of symptom severity in the OCD and body dysmorphic disorder group suggest that the observed differences in insight are not correlated with illness severity. Some other studies, however, reported that poor insight OCD patients responded as well to behavior therapy as those with good insight. ${ }^{55,56}$ Steketee and Shapiro ${ }^{57}$ reported inconsistent findings about the relation between insight and treatment response in OCD patients, and they suggested that such results may be due to the difficulty of measuring the insight and the instability of the concept. In our study 41 of patients are responders and 40 of them has good insight according to YBOCS (0-1-2 points of YBOCS insight question); 17 of 30 resistant patients has bad insight (3-4 points of YBOCS insight question). So, our study seems to be similar to studies showing relation between poor insight and treatment resistance.

The relationship between poor insight and treatment response may be direct or due to different clinical variables. Insight and treatment response were both associated with some clinical variables as OCD severity, ${ }^{58}$ comorbid illnesses (especially depression and other anxiety disorders) ${ }^{17,59}$ and symptom subtype. ${ }^{53,60,61}$

Poor insight has been associated with psychiatric comor- bidity. ${ }^{17,59}$ OCD with poor insight has been associated with greater comorbidity rate of depression and anxiety, ${ }^{54}$ and long duration of illness. ${ }^{59}$

Recent clinical empirical studies demonstrated that poor insight has been associated with severe symptoms. ${ }^{51,59}$ Positive correlations between poor insight, severity of obsession and compulsion, especially autogenous obsessive symptoms, compulsive hoarding were suggested to increase the risk of depression in OCD. ${ }^{62}$ Moreover, affective status especially depression influence OCD in different ways. Firstly, improvement in depressive symptoms is found to be accompanied by improvement in insight, ${ }^{21}$ secondly OCD with comorbid severe depression diminishes patients' ability to deal with symptoms, ${ }^{54}$ contributes to the converting of obsessions into delusional beliefs; ${ }^{63}$ and reduces the perception of the absurdity of the obsessions. ${ }^{54}$

The resistant group in our study had significantly higher mean scores of depression, anxiety, duration of illness and insight subscale scores than the responders' group. Duration of the illness and comorbidity of depression or anxiety have been reported as being negatively linked to treatment resistance in patients with OCD in research. ${ }^{13,61,64}$

According to the recent literature poor insight and the symptom type of OCD are related to each other. Previous studies have demonstrated that a higher proportion of poor insight OCD patients are having severe hoarding symptoms ${ }^{60,65,66}$ and symmetry symptoms. ${ }^{53,66,67}$ Fear of contamination/washing has been correlated with both good ${ }^{54}$ and poor insight ${ }^{66}$ Insight in OCD patients has been interpreted in some different ways. Although obsessions and delusions are usually taken as dichotomous phenomena, some authors propose insight as a concept on a continuum ${ }^{68}$ from overvalued ideas to delusional thinking. OCD patients are usually aware of their abnormality ${ }^{69}$ and are aware that other people consider their beliefs absurd, often find their compulsions senseless but feel the need to perform them anyway. In con- 
trast, many patients with some OCD spectrum disorders as body dysmorphic disorder believe that others agree that they are ugly and that their beliefs are not caused by a psychiatric illness but are true. ${ }^{53}$

In a study of 545 consecutive patients with a primary diagnosis of OCD those who were in the poor insight subgroup had significantly higher scores on the Y-BOCS compulsions and Y-BOCS total score with contamination fears and washing compulsions. In the same study good insight group had a significantly higher frequency of aggressive obsessions and forbidden thoughts. ${ }^{70}$

In a comprehensive assessment of 824 outpatients with OCD, Jakubovski et al. ${ }^{66}$ suggested that after controlling for current severity of OCD, age, and gender; increased severity of present and worst-ever hoarding symptoms and a higher rate of joblessness were associated with poor insight. Poor insight has been associated mainly with hoarding obsessions and related collecting compulsions $s^{172,21,65,66}$ and with somatic obsessions. ${ }^{15,65,71}$

In our study the resistant group had higher scores on religious and somatic symptoms and compulsions of ordering/ arranging. In the traditional Turkish society religiosity rather frequently takes a central role in life so these symptoms are less acceptable and forbidden thoughts with religious concept are a major reason for seeking help. Somatic complaints, not psychiatric ones, are sometimes the only way to gain medical assistance.

The focus in earlier research was mostly on the relation between insight, demographic features and the severity of the symptoms without taking the mentalizing ability into account. However, the relationship between treatment resistance and insight may be mediated by several factors. After controlling for some relevant factors including duration of illness, anxiety, depression, obsession scores, compulsion scores, treatment resistance were no longer significantly related to insight. Mentalizing ability emerged to have a significant association with insight when taking all possible mediating factors into account. The severity of anxiety and depressive symptoms were found to have no effect. The mediating role of the mentalizing skills appears to be the only important factor.

Mentalizing is known as the ability to predict emotional state from facial expressions and to infer mental state from knowledge about persons' beliefs and view point. ${ }^{24}$ Clinical studies comparing OCD patients to normal subjects have reported that emotional awareness and perception deficits are more prevalent among patients with OCD. OCD patients indicated poorer performance on mentalizing tasks than healthy controls. ${ }^{26,31}$ Several studies show that OCD patients have difficulties in emotional perception and empathy. ${ }^{32,33}$ Kang et al..$^{32}$ emphasized that emotional awareness deficit may be impor- tant in maintenance of obsessive-compulsive symptoms.

Operational thinking, absence of fantasies and symbolic capacity was identified in the greater number of OCD patients. ${ }^{65}$ The main characteristics of this style of thinking are predictors of poor mentalizing ability. ${ }^{72}$

To date, only a limited number of studies investigating the correlation between insight and mentalizing skills are studied in schizophrenia patients. ${ }^{35,73}$ Bora et al..$^{35}$ suggested that mentalizing abilities are very important for the awareness of illness in schizophrenia patients and that these two concepts are very similar. It is also asserted that poor insight could be a mentalizing deficit. Langdon and Ward, ${ }^{36}$ found that impaired mentalizing predicts poor insight. Lysaker et al. ${ }^{28}$ and David $^{34}$ indicated that association of mentalizing and insight points to a direct connection. Despite the different clinical sample our findings are consistent with earlier research.

Previous research show that representations of self and others are related to each other. We found that mentalizing ability was the strongest predictor of insight using YBOCS insight subscale which is evaluating insight related to symptoms and the disease. On the other hand, BABS takes insight as a dynamic concept on a spectrum.

Meta analytic data about mentalizing confirmed the presence of mentalizing deficits in psychotic patients independent of IQ, age and gender. ${ }^{74}$ An earlier investigation on mentalization and psychosis reported that mentalization deficits could be a potentially moderating factor for the risk to develop psychotic disorders. A recent study hypothesized that there are two protective factors for psychosis: attachment security and mentalizing. Treatment based on strengthening the mentalizing abilities is shown to improve the outcome in borderline patients. ${ }^{75,76}$

Moreover, mentalizing deficits in psychotic patients have been related to impaired social functioning, ${ }^{77}$ poor insight $t^{35}$ and delusions. ${ }^{74}$

The resistant group of our study has a 21.97 mean score of BABS which means that patients are at the delusional end of the insight spectrum. Similar to finding psychotic patients with delusions, impaired mentalizing is not a surprising result for our sample.

The overlap between mentalizing and insight may be interpreted in some different ways. There are some overlapping brain regions, which are considered to be involved both in mentalizing abilities and the neurobiology of OCD. Firstly, most basal ganglia disorders have been reported to cause mentalizing deficits; subcortical structures such as the basal ganglia (BG) have been attributed to the mentalizing ability especially to the affective subcomponent. ${ }^{78}$ Secondly, OCD is frequently seen in patients with basal ganglia dysfunctions such as Tourette's syndrome, Sydenham's chorea and Hun- 
tington's disease. Obsessive-compulsive symptoms in several neurological disorders affecting the basal ganglia confirm its role in the pathophysiology of OCD..$^{79,80}$ Basal ganglia is an area where the serotonin and dopamine systems interact extensively and these two systems are important in the pathophysiology of the disease. ${ }^{81}$ The BG might be involved in mentalizing abilities also due to its impact on emotion recognition and facial expression decoding. ${ }^{82}$ Mentalizing and attachment are close knitted concepts that are both affected by oxytocinergic system ${ }^{83,84}$ which is also related to the OCD symptoms. $^{85}$

In closing a number of limitations need to be acknowledged regarding the present study. Mentalization was measured using the RMET. Using a different mentalization measures is important for the affective and cognitive subcomponents of mentalizing. RMET according to some research is able to measure mostly the affective component of this ability. ${ }^{86}$

In this study, we only measured the total score of BABS, but we have not investigated every single item of the following components of insight: conviction that the belief is accurate, perception of others' views of the belief, explanation for differing views, willingness to consider that the belief is wrong, and recognition that the belief has a psychiatric/psychological cause.

The association between insight and mentalizing may be bi-directional. The level of insight could be correlated with the mentalizing ability of patients with OCD. Assessment of insight should be performed both with clinical interview and self-report instruments.

A clinical comparison group was not studied so it remains unclear whether these findings are specific for the OCD patients. Studies should be conducted with the healthy relatives of patients with OCD and examine the effects of family history, such as the frequency of psychotic illnesses and basal ganglia dysfunctions in the extended family.

Furthermore, pharmacological and neurobiological studies will elucidate different pathways of insight and mentalizing abilities into OCD concerning basal ganglia, dopaminergic, serotonergic and oxytocinergic systems in order to provide better treatment programs for treatment-resistant OCD patients.

Despite the limitations, the present study could make several contributions to the current literature. To our knowledge, this is the first study to evaluate relationship between mentalizing, insight and treatment resistance in a sample of OCD patients. Mentalization based therapies might be useful for improving the insight of the OCD patients and to identify effective strategies for the management of this subgroup of patients.

\section{Previous Presentations of the Research}

Poster Presentation at 7th International Congress on Psychopharmacology \& 3rd International Symposium on Child and Adolescent Psychopharmacology (7th ICP-3rd ISCAP) 15-19 Nisan 2015, Abstract Published at Bulletin of Clinical Psychopharmacology 2015;25(Suppl. 1):S178.

\section{REFERENCES}

1. Stein DJ. Obsessive-compulsive disorder. Lancet 2002;360:397-405.

2. Jenike MA. Obsessive-compulsive disorder. N Engl J Med 2004;350: 259-265.

3. Pallanti S, Grassi G, Cantisani A. Emerging drugs to treat obsessivecompulsive disorder. Expert Opin Emerg Drugs 2014;19:67-77.

4. Bloch MH, Landeros-Weisenberger A, Kelmendi B, Coric V, Bracken MB, Leckman JF. A systematic review: antipsychotic augmentation with treatment refractory obsessive-compulsive disorder. Mol Psychiatry 2006;11:622-632.

5. Khalsa SS, Schiffman JE, Bystritsky A. Treatment-resistant OCD: options beyond first-line medications. Curr Psychiatry 2011;10:44-52.

6. Pallanti S, Hollander E, Bienstock C, Koran L, Leckman J, Marazziti D, et al. Treatment non-response in OCD: methodological issues and operational definitions. Int J Neuropsychopharmacol 2002;5:181-191.

7. Hollander E, Baldini Rossi N, Sood E, Pallanti S. Risperidone augmentation in treatment-resistant obsessive-compulsive disorder: a doubleblind, placebo-controlled study. Int J Neuropsychopharmacol 2003;6: 397-401.

8. Albert U, Aguglia A, Bramante S, Bogetto F, Maina G. Treatment-resistant obsessive-compulsive disorder (OCD): current knowledge and open questions. Clin Neuropsychiatry 2013;10:19-30.

9. Alonso P, Menchon JM, Pifarre J, Mataix-Cols D, Torres L, Salgado P, et al. Long-term follow-up and predictors of clinical outcome in obsessive-compulsive patients treated with serotonin reuptake inhibitors and behavioral therapy. J Clin Psychiatry 2001;62:535-540.

10. Ackerman DL, Greenland S, Bystritsky A. Side effects as predictors of drug response in obsessive-compulsive disorder. J Clin Psychopharmacol 1999;19:459-465.

11. Erzegovesi S, Cavallini MC, Cavedini P, Diaferia G, Locatelli M, Bellodi L. Clinical predictors of drug response in obsessive-compulsive disorder. J Clin Psychopharmacol 2001;21:488-492.

12. Kim CH, Jeong JW, Kim EJ, Shin YS, Suh HS, Lee HS, et al. Clinical predictors of drug response in patients with obsessive-compulsive disorder. Clin Psychopharmacol Neurosci 2011;9:23-28.

13. Semiz UB, Inanc L, Bezgin CH. Are trauma and dissociation related to treatment resistance in patients with obsessive-compulsive disorder? Soc Psychiatry Psychiatr Epidemiol 2014;49:1287-1296.

14. Maltby N, Tolin DF. Overview of treatments for obsessive-compulsive disorder and spectrum conditions: conceptualization, theory, and practice. Br Treat Cris Interv 2003;3:127-144.

15. Marazziti D, Picchetti M, Baroni S, Ceresoli D, Consoli G, Catena Dell'Osso M. Current pharmacological and non pharmacological treatments for obsessive-compulsive disorder. J Psychopathol 2012;18:5-18.

16. Koran LM, Hollander E, Nestadt G, Simpson HB. Practice Guideline for the treatment of patients with obsessive-compulsive disorder. Am J Psychiatry 2007;64(7 suppl):5-53.

17. Kishore VR, Samar R, Janardhan Reddy YC, Chandrasekhar CR, Thennarasu K. Clinical characteristics and treatment response in poor and good insight obsessive-compulsive disorder. Eur Psychiatry 2004;19:202-208.

18. Shetti CN, Reddy YCJ, Kandavel T, Kashyap K, Singisetti S, Hiremath AS, et al. Clinical predictors of drug nonresponse in obsessive-compulsive disorder. J Clin Psychiatry 2005;66:1517-1523.

19. Hantouche EG, Bouhassira M, Lancrenon S. Prospective follow-up over a 12 month period of a cohort of 155 patients with obsessivecompulsive disorder: phase III National DRT-TOC Study. Encephale 
2000;26:73-83.

20. Catapano F, Sperandeo R, Perris F, Lanzaro M, Maj M. Insight and resistance in patients with obsessive-compulsive disorder. Psychopathology 2001;34:62-68.

21. Matsunaga H, Kiriike N, Matsui T, Oya K, Iwasaki Y, Koshimune K, et al. Obsessive-compulsive disorder with poor insight. Compr Psychiatry 2002;43:150-157.

22. Ng R, Fish S, Granholm E. Insight and theory of mind in schizophrenia. Psychiatry Res 2015;225:169-174.

23. Frith U, Happé F. Autism: beyond "theory of mind." Cognition 1994; 50:115-132.

24. Frith C, Frith U. Theory of mind. Curr Biol 2005;15:R644-R645.

25. Ntouros E, Bozikas VP, Andreou C, Kourbetis D, Lavrentiadis G, Garyfallos G. Emotional perception and theory of mind in first episode psychosis: the role of obsessive-compulsive symptomatology. Psychiatry Res 2014;220:112-117.

26. Darvishi N, Alilou MM, Bakhshipour A, Farnam A, Bahramkhani M. Theory of mind in obsessive-compulsive disorder patients versus normal individuals. Adv Cogn Sci 2013;15:77-89.

27. Islam L, Scarone S, Gambini O. First- and third-person perspectives in psychotic disorders and mood disorders with psychotic features. Schizophr Res Treatment 2011;2011:769136.

28. Lysaker PH, Carcione A, Dimaggio G, Johannesen JK, Nicolò G, Procacci M, et al. Metacognition amidst narratives of self and illness in schizophrenia: Associations with neurocognition, symptoms, insight and quality of life. Acta Psychiatr Scand 2005;112:64-71.

29. Fonagy P, Gergely G, Jurist EL, Target M. Affect Regulation, Mentalization and the Development of the Self. New York: Karnac Books; 2004.

30. Bateman AW, Fonagy P. Handbook of Mentalizing in Mental Health Practice. Arlington: American Psychiatric Pub; 2012.

31. Sayin A, Oral N, Utku C, Baysak E, Candansayar S. Theory of mind in obsessive-compulsive disorder: comparison with healthy controls. Eur Psychiatry 2010;25:116-122.

32. Kang JI, Namkoong K, Yoo SW, Jhung K, Kim SJ. Abnormalities of emotional awareness and perception in patients with obsessive-compulsive disorder. J Affect Disord 2012;141:286-293.

33. Grisham JR, Norberg MM. Compulsive hoarding: current controversies and new directions. Dialogues Clin Neurosci 2010;12:233-240.

34. David AS. "To see oursels as others see us". Aubrey Lewis's insight. Br J Psychiatry 1999;175:210-216.

35. Bora E, Sehitoglu G, Aslier M, Atabay I, Veznedaroglu B. Theory of mind and unawareness of illness in schizophrenia: is poor insight a mentalizing deficit? Eur Arch Psychiatry Clin Neurosci 2007;257:104-111.

36. Langdon R, Ward P. Taking the perspective of the other contributes to awareness of illness in schizophrenia. Schizophr Bull 2009;35:1003-1011.

37. First MB, Gibbon M, Spitzer RL, Williams JBW. Structured Clinical Interview for DSM-IV Axis II Personality Disorders (SCID-II). Washington DC: American Psychiatric Press; 1997.

38. Goodman WK, Price LH, Rasmussen SA, Mazure C, Fleischmann RL, Hill CL, et al. The Yale-Brown Obsessive Compulsive Scale: I. development, use, and reliability. Arch Gen Psychiatry 1989;46:1006-1011.

39. Tek C, Uluğ B, Rezaki BG, Tanriverdi N, Mercan S, Demir B, et al. Yale-Brown Obsessive Compulsive Scale and US National Institute of Mental Health Global Obsessive Compulsive Scale in Turkish: reliability and validity. Acta Psychiatr Scand 1995;91:410-413.

40. Hisli Şahin N. A study on the validity of Beck Depression Inventory in Turkish. Turkish J Psychol 1988;7:3-13.

41. Beck AT, Ward CH, Mendelson M, Mock J, Erbaugh J. An inventory for measuring depression. Arch Gen Psychiatry 1961;4:561-571.

42. Beck AT, Epstein N, Brown G, Steer RA. An inventory for measuring clinical anxiety: psychometric properties. J Consult Clin Psychol 1988; 56:893-897.

43. Ulusoy M, Sahin N, Erkmen H. Turkish version of the Beck Anxiety Inventory: psychometric properties. J Cogn Psychother An Int Q 1998;
12:163-172.

44. Baron-Cohen S, Wheelwright S, Hill J, Raste Y, Plumb I. The "Reading the Mind in the Eyes" Test revised version: a study with normal adults, and adults with Asperger syndrome or high-functioning autism. J Child Psychol Psychiatry 2001;42:241-251.

45. Yildirim EA, Kaşar M, Güdük M, Ateş E, Küçükparlak I, Ozalmete EO. Investigation of the reliability of the "reading the mind in the eyes test” in a Turkish population. Turk Psikiyatr Derg 2011;22:177-186.

46. Eisen JL, Phillips KA, Baer L, Beer DA, Atala KD, Rasmussen SA. The brown assessment of beliefs scale: reliability and validity. Am J Psychiatry 1998;155:102-108.

47. Özcan T, Erkan K, Şafak Y, Karadere ME, Yavuz KF, Türkçapar MH. Brown assessment of beliefs scale: a study of reliability and validity. J Cogn Psychother Res 2013;2:25-33.

48. Stewart SL, Corcoran R, Lewis SW, Drake RJ. The relationship between theory of mind and insight in psychosis: evidence for specificity. Psychosis 2010;2:34-40.

49. Quee PJ, van der Meer L, Krabbendam L, de Haan L, Cahn W, Wiersma D, et al. Insight change in psychosis: relationship with neurocognition, social cognition, clinical symptoms and phase of illness. Acta Psychiatr Scand 2014;129:126-133.

50. Catapano F, Perris F, Fabrazzo M, Cioffi V, Giacco D, De Santis V, et al. Obsessive-compulsive disorder with poor insight: a three-year prospective study. Prog Neuropsychopharmacol Biol Psychiatry 2010;34:323-330.

51. Solyom L, DiNicola VF, Phil M, Sookman D, Luchins D. Is there an obsessive psychosis? Aetiological and prognostic factors of an atypical form of obsessive-compulsive neurosis. Can J Psychiatry 1985;30:372-380.

52. Praško J, Raszka M, Adamcova K, Grambal A, Koprivova J, Kudrnovs$\mathrm{ka} \mathrm{H}$, et al. Predicting the therapeutic response to cognitive behavioural therapy in patients with pharmacoresistant obsessive-compulsive disorder. Neuroendocrinol Lett 2009;30:615-623.

53. Eisen JL, Phillips KA, Coles ME, Rasmussen SA. Insight in obsessive compulsive disorder and body dysmorphic disorder. Compr Psychiatry 2004;45:10-15.

54. Alonso P, Menchón JM, Segalàs C, Jaurrieta N, Jiménez-Murcia S, Cardoner N, et al. Clinical implications of insight assessment in obsessive-compulsive disorder. Compr Psychiatry 2008;49:305-312.

55. Lelliott PT, Noshirvani HF, Başoğlu M, Marks IM, Monteiro WO. Obsessive-compulsive beliefs and treatment outcome. Psychol Med 1988; 18:697-702.

56. Ito LM, De Araujo LA, Hemsley DR, Marks IM. Beliefs and resistance in obsessive-complulsive disorder: observations from a controlled study. J Anxiety Disord 1995;9:269-281.

57. Steketee G, Shapiro LJ. Predicting behavioral treatment outcome for agoraphobia and obsessive compulsive disorder. Clin Psychol Rev 1995; 15:317-346.

58. Türksoy N, Tükel R, Ozdemir O, Karali A. Comparison of clinical characteristics in good and poor insight obsessive-compulsive disorder. J Anxiety Disord 2002;16:413-423.

59. Bellino S, Patria L, Ziero S, Bogetto F. Clinical picture of obsessivecompulsive disorder with poor insight: a regression model. Psychiatry Res 2005;136:223-231.

60. Samuels J, Yin YS, Grados MA, Willour VL, Bienvenu OJ, Greenberg $\mathrm{BD}$, et al. Significant linkage to compulsive hoarding on chromosome 14 in families with obsessive-compulsive disorder: results from the OCD collaborative genetics study. Am J Psychiatry 2007;164:493-499.

61. Saxena S, Maidment KM, Vapnik T, Golden G, Rishwain T, Rosen RM, et al. Obsessive-compulsive hoarding: symptom severity and response to multimodal treatment. J Clin Psychiatry 2002;63:21-27.

62. Altintaş E, Taşkintuna N. Factors associated with depression in obsessive-compulsive disorder: a cross-sectional study. Noropsikiyatri Ars 2015;52:346-353.

63. Butler G, Mathews A. Cognitive processes in anxiety. Adv Behav Res Ther 1983;5:51-62. 
64. Pigott TA, Seay S. Pharmacotherapy of obsessive-compulsive disorder. Int Rev Psychiatry 1997;9:133-147.

65. De Berardis D, Campanella D, Gambi F, Sepede G, Salini G, Carano A, et al. Insight and alexithymia in adult outpatients with obsessive-compulsive disorder. Eur Arch Psychiatry Clin Neurosci 2005;255:350-358.

66. Jakubovski E, Pittenger C, Torres AR, Fontenelle LF, do Rosario MC, Ferrão YA, et al. Dimensional correlates of poor insight in obsessivecompulsive disorder. Prog Neuropsychopharmacol Biol Psychiatry 2011;35:1677-1681.

67. Elvish J, Simpson J, Ball LJ. Which clinical and demographic factors predict poor insight in individuals with obsessions and/or compulsions? J Anxiety Disord 2010;24:231-237.

68. Fornaro M, Gabrielli F, Mattei C, Vinciguerra V, Fornaro P. Aripiprazole augmentation in poor insight obsessive-compulsive disorder: a case report. Ann Gen Psychiatry 2008;7:26.

69. Szechtman H, Woody E. Obsessive-compulsive disorder as a disturbance of security motivation. Psychol Rev 2004;111:111-127.

70. Cherian AV, Narayanaswamy JC, Srinivasaraju R, Viswanath B, Math SB, Kandavel T, et al. Does insight have specific correlation with symptom dimensions in OCD? J Affect Disord 2012;138:352-359.

71. Kumar H. Symptom dimensions and clinical presentations in obsessive compulsive disorder. Int J Indian Psychol 2016;59:116.

72. Gubb K. Psychosomatics today: a review of contemporary theory and practice. Psychoanal Rev 2013;100:103-143.

73. Drake RJ, Lewis SW. Insight and neurocognition in schizophrenia. Schizophr Res 2003;62:165-173.

74. Harrington L, Siegert RJ, McClure J. Theory of mind in schizophrenia: a critical review. Cogn Neuropsychiatry 2005;10:249-286.

75. Bateman A, Fonagy P. 8-year follow-up of patients treated for borderline personality disorder: mentalization-based treatment versus treatment as usual. Am J Psychiatry 2008;165:631-638.

76. Bateman A, Fonagy P. Randomized controlled trial of outpatient mentalization-based treatment versus structured clinical management for borderline personality disorder. Am J Psychiatry 2009;166:1355-1364.
77. Fett AKJ, Viechtbauer W, Dominguez M de G, Penn DL, van Os J, Krabbendam L. The relationship between neurocognition and social cognition with functional outcomes in schizophrenia: a meta-analysis. Neurosci Biobehav Rev 2011;35:573-588.

78. Bodden ME, Kübler D, Knake S, Menzler K, Heverhagen JT, Sommer J, et al. Comparing the neural correlates of affective and cognitive theory of mind using fMRI: involvement of the basal ganglia in affective theory of mind. Adv Cogn Psychol 2013;9:32-43.

79. Miguel EC, Rauch SL, Jenike MA. Obsessive-compulsive disorder. Psychiatr Clin North Am 1997;20:863-883.

80. Maia AS, Barbosa ER, Menezes PR, Miguel Filho EC. Relationship between obsessive-compulsive disorders and diseases affecting primarily the basal ganglia. Rev Hosp Clin Fac Med Sao Paulo 1999;54:213-221.

81. Di Matteo V, Pierucci M, Esposito E, Crescimanno G, Benigno A, Di Giovanni G. Serotonin modulation of the basal ganglia circuitry: therapeutic implication for Parkinson's disease and other motor disorders. Prog Brain Res 2008;172:423-463.

82. Assogna F, Pontieri FE, Caltagirone C, Spalletta G. The recognition of facial emotion expressions in Parkinson's disease. Eur Neuropsychopharmacol 2008;18:835-848.

83. Tas C, Brown EC, Gonzalez C, Brüne M. Experimental Usage of Oxytocin to Combat Deficits in Social Cognition in Schizophrenia. In: Lysaker PH, Dimaggio G, Brüne M, Editors. Social Cognition and Metacognition in Schizophrenia: Psychopathology and Treatment Approaches. San Diego, CA, USA: Academic Press/Elsevier, 2014, p.301-312.

84. Brent BK. A mentalization-based approach to the development of the therapeutic alliance in the treatment of schizophrenia. J Clin Psychol 2015;71:146-156.

85. Humble MB, Uvnäs-Moberg K, Engström I, Bejerot S. Plasma oxytocin changes and anti-obsessive response during serotonin reuptake inhibitor treatment: a placebo controlled study. BMC Psychiatry 2013;13:344.

86. Oakley BFM, Brewer R, Bird G, Catmur C. Theory of mind is not theory of emotion: a cautionary note on the reading the mind in the eyes test. J Abnorm Psychol 2016;125:818-823. 